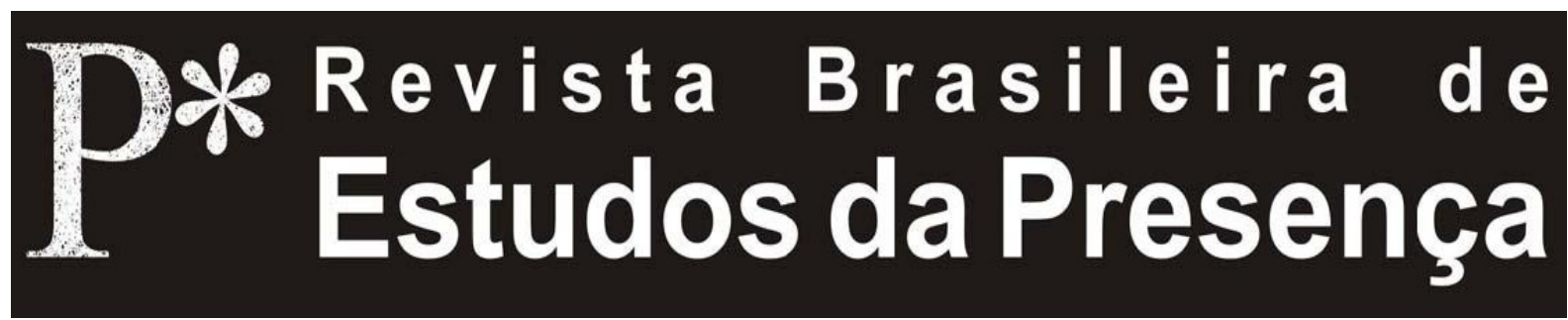

DOI - http://dx.doi.org/10.1590/2237-266026112

ISSN 2237-2660

\title{
Venezuela 1976: 0 encontro entre o odin Teatret e os Yanomamis
}

Arianna Berenice De Sanctis

Université Paris 8 Vincennes Saint-Denis - Saint-Denis, França

RESUMO - Venezuela 1976: o encontro entre o Odin Teatret e os Yanomamis - O texto descreve o encontro, em 1976, do Odin Teatret e os índios Yanomamis, a partir da participação do grupo dinamarquês no Festival de Caracas (Venezuela), para apresentação do espetáculo Come! And the day will be ours. Discute-se essa viagem, como uma etapa fundamental na história do Odin, pois trata-se da primeira vez que o grupo todo se apresenta na América Latina. Narra-se a permanência do Odin Teatret durante seis semanas na Venezuela e a organização de um troc com os índios Yanomamis, uma comunidade ao norte do rio Orénoque, na Amazônia venezuelana. Os dados analisados são provenientes dos arquivos do CTLS (Holstebro, Dinamarca) assim como de entrevistas e de testemunhos dos atores do Odin Teatret. Usa-se uma perspectiva etnocenológica de análise.

Palavras-chave: Odin Teatret. Venezuela. Yanomamis. Aprendizagem. Sensorialidade.

ABSTRACT - Venezuela 1976: the meeting of Odin Teatret with the Yanomamis - In 1976, Odin Teatret was invited to the Festival of Caracas (Venezuela) to present the performance Come! And the day will be ours. That journey is a landmark in the history of Odin since it was the first time the whole group went to Latin America. The Odin Teatret group remained six weeks in Venezuela. In this period, the group organized a barter with the Yanomamis, an indigenous community of the Upper Orinoco in the Amazonian Rainforest. This barter is the main topic of our analysis; it is of particular relevance for studying the phenomena related to learning and sensoriality. Our study is based on selected material from the CTLS' archive (Hölstebro, Denmark) and on interviews with the Odin Teatret's actors. We analysed our material from an ethnoscenological point of view.

Keywords: Odin Teatret. Venezuela. Yanomamis. Learning. Sensoriality.

RÉSUMÉ - Venezuela 1976: la rencontre entre l'Odin Teatret et les Yanomamis - En 1976, l'Odin Teatret est invité au Festival de Caracas (Venezuela) pour présenter le spectacle Come! And the day will be ours. Ce voyage marque une étape fondamentale dans l'histoire de l'Odin car il s'agit de la première fois que le groupe est présent au complet sur le territoire latino-américain. L'Odin reste sur place pendant six semaines et, dans cette période, il organise un troc avec les Yanomamis, une communauté indigène de l'Orénoque supérieur en Amazonie vénézuélienne. La recherche dans les archives du CTLS (Holstebro, Danemark) ainsi que les entretiens et les témoignages des acteurs de l'Odin Teatret ont fourni les éléments pour l'étude de cet événement, analysé dans une perspective ethnoscénologique.

Mots-clés: Odin Teatret. Venezuela. Yanomamis. Apprentissage. Sensorialité. 


\section{Introdução}

Em 1976, o grupo de teatro dinamarquês Odin Teatret foi convidado para ir à Venezuela por ocasião do Festival de Caracas. O grupo permanece lá durante seis semanas entre os meses de abril e maio de 1976. Durante esse período, o grupo participa do Festival de Caracas (de 18 de abril a 12 de maio), assim como realiza diversos trocs $^{1}$ na periferia e arredores de Caracas. Para encerrar a experiência venezuelana, o grupo foi igualmente convidado a organizar um troc com os Yanomamis, comunidade indígena localizada no norte do rio Orénoque, na Amazônia venezuelana. Essa viagem marca uma etapa fundamental na história do Odin, pois é a primeira vez que o grupo todo esteve presente em território latino-americano. Nessa ocasião, o Odin entra em contato com grupos de teatro e com artistas latino-americanos com os quais, ao longo dos anos, ele estabelece uma relação de amizade e colaboração duráveis e muito significativas em nível pessoal e profissional: "Foi nosso primeiro encontro com os grupos latino-americanos, e ele teve uma grande influência sobre a maneira de ver o teatro de grupo e sua posição na história do teatro contemporâneo" (Rasmussen, 2006, p. 87).

Quando o grupo chega à Venezuela, o país se encontra numa situação fortemente contraditória. A Venezuela, em função da nacionalização do petróleo, tem um acentuado desenvolvimento econômico, mas, apesar disso, a má administração dos recursos, a burocracia e a corrupção, ocasionam uma distribuição injusta das riquezas, o que engendra diferenças consideráveis entre a classe pobre e as elites. Alguns anos mais tarde, essas mesmas causas levam o país a uma dívida exterior muito elevada, o que aumenta ainda mais as diferenças sociais e provoca, por consequência, protestos e tumultos sociais na cidade de Caracas e nos seus arredores. Essa cidade foi vivenciada pelo Odin em toda sua complexidade: ela transbordava contradições. Se, de um lado, o bum econômico provoca a modernização das infraestruturas; de outro, a pobreza e a falta de continuidade na liberação de recursos caracterizavam a maior parte da comunidade local. 
No mesmo período, organiza-se em Caracas um colóquio do ITI (International Theatre Institut-Unesco) sobre o futuro do teatro no terceiro mundo. Esse colóquio acontece no momento em que as condições sociais difíceis observadas na Venezuela incitaram o Odin a se interrogar sobre o sentido e a necessidade do teatro no continente latino-americano: "Mas que sentido pode ter fazer teatro hoje na América Latina, numa realidade sociocultural tão dramática, onde as tensões são tão agudas e as tragédias tão manifestas?" (Barba, 1999, p. 217).

O grupo examina o problema da atividade teatral num contexto como o da Venezuela: "Que desperdício organizar um grande colóquio internacional de teatro! Não seria uma maneira de fechar os olhos para um problema bem mais grave? [...] O futuro do teatro no terceiro mundo? Isso não seria o exemplo de um problema banal?" (Barba, 1999, p. 217).

A reação do Odin nasce do contraste entre as condições concretas de existência dos grupos teatrais e uma temática que lhes parece teórica e completamente afastada das suas preocupações.

O Odin se opõe, durante toda sua existência, a esta ideia muitas vezes repetida de que o teatro tem um valor próprio que agiria num plano paralelo ao contexto. Sua interação com a comunidade se desenvolve no plano individual, criando ligações em nível político e socioeconômico menos evidentes, porém mais eficazes.

Esse encontro com a realidade latino-americana, sem dúvida, facilitou e reforçou a tomada de consciência pelo grupo do valor intrínseco do performer, tanto no plano artístico, quanto no plano pedagógico e da ética grupal. Além disso, a experiência venezuelana forneceu para o diretor estímulos que o conduziram à teorização de um novo tipo de teatro contemporâneo. A marginalidade e a exclusão ligadas ao conceito de Terceiro Mundo conduziram Barba a nomear esse movimento como Terceiro Teatro, apenas alguns meses depois da viagem à Venezuela² . 


\title{
O troc
}

A ideia de troc, que já havia sido concebida e experimentada pela primeira vez durante a viagem do Odin a Salento (Pouilles; Italie, 1974) é retomada novamente pelo grupo em numerosas situações durante sua presença em território venezuelano. O troc é um instrumento que permite ao grupo aproximar realidades marginais por intermédio de trocas recíprocas de suas praticas artísticas.

\begin{abstract}
A ideia de troca não é a de encontrar uma 'nova linguagem teatral' ou uma nova forma de expressão estética. A troca é, entretanto, uma tentativa de usar o teatro em um outro sentido, de uma maneira política ou de organização da comunidade: para criar uma situação que permita o contato entre atores e espectadores a despeito de suas diferenças e respectivas individualidades, especificamente em função da fascinação que a diferença engendra. [...] A troca é um intercâmbio entre diferentes culturas em forma de dança, música, canção e ritual, pedagogia e performances (Christoffersen, 1993, p. 62).
\end{abstract}

Além disso, essa prática permite ao Odin interagir com comunidades normalmente excluídas do circuito cultural convencional, atingindo, assim, um público não especializado e alargando o campo de ação do grupo.

Durante sua presença em Caracas, o Odin reivindica uma autonomia parcial em relação ao Festival, devido aos mal-entendidos e até conflitos com os organizadores. Entre outros, o grupo recusou-se a se hospedar num hotel de luxo e preferiu alugar uma casa na periferia da cidade. Sua localização limítrofe lhe permitiu entrar em contato com as comunidades locais e com os grupos teatrais não ligados diretamente ao Festival. O grupo organizou trocs em bairros da periferia e foi também a Curiepe (em 7 de maio), um lugarejo numa região de cultura negra de Barlovento, a $200 \mathrm{~km}$ de Caracas (D’Urso; Taviani, 1977).

\section{O troc com os Yanomamis}

O grupo foi convidado a organizar um troc de 13 a 21 de maio de 1976, com a comunidade Yanomami. Trata-se de um 
dos primeiros trocs realizados na América Latina, e o único do Odin, que foi desenvolvido em meio a uma comunidade indígena. Kurare, uma cooperativa cinematográfica local, que assistiu ao troc de Barlovento, foi surpreendida pelos meios expressivos dos elementos espetaculares apresentados. Além disso, os membros dessa cooperativa falaram na imprensa sobre o fato de terem percebido analogias e pontos em comum entre o teatro do Odin e as cerimônias sagradas dos Yanomamis. Seu desejo foi, então, de colocar em contato as duas comunidades a fim de que elas pudessem se conhecer e trocar seus rituais. A essa proposta, que surpreende e inquieta ao mesmo tempo o diretor do Odin Teatret, ele responde primeiro com entusiasmo, mas, num segundo momento, se perguntando sobre as incoerências de uma tal experiência:

Que sentido pode ter fazer teatro numa aldeia, essa arte importada, lá onde vivem os rituais, as festas, manifestações coletivas e populares que possuem uma força infinitamente superior em relação a qualquer espetáculo teatral com um punhado de espectadores? (Barba, 1999, p. 217).

Ele se questiona, da mesma forma, sobre a comunicação com os índios por intermédio do teatro: "Isso é um projeto insensato, nós dissemos aos antropólogos, quando eles nos propuseram ir. Para os Yanomamis, nosso teatro não quer dizer nada. Não existe nenhuma possibilidade de comunicação [...]" (Barba, 1999, p. 218).

Apesar de todas as resistências e dúvidas de Eugenio Barba em um primeiro momento, os organizadores não renunciaram ao projeto. Para valorizar sua intenção para o Odin, eles se apoiaram sobre o valor antropológico do seu convite. Em primeiro lugar, os cineastas promoveram esse encontro a fim de permitir que os índios pudessem se confrontar com uma faceta ignorada do homem branco: "Eles viram apenas missionários, antropólogos e funcionários do governo. Nós queríamos lhes mostrar uma face desconhecida do homem branco [...]" (Barba, 1999, p. 218). Segundo, eles queriam encorajar o contato relacional entre duas microssociedades, a indígena e a teatral, para comparar suas formas expressivas e 
seus meios de comunicação: "Na realidade, pretendia-se saber se o grupo Odin e suas teorias se harmonizariam com a estrutura da linguagem indígena [...], notadamente a de um grupo primitivo, como os índios Yanomamis" (Trujillo, 1976, p. n.i.).

Os membros da cooperativa estimam que as duas linguagens, artística de um lado e ritualística de outro, teriam princípios comuns que poderiam facilitar a comunicação entre os dois grupos, através de meios inabituais e frequentemente negligenciados. Eles esperavam, além disso, favorecer uma comunicação pré-verbal por intermédio da arte.

\section{A Equipe}

O troc foi o resultado de uma colaboração interdisciplinar. Nessa expedição, tomaram parte diversas pessoas vindas de formações e de experiências diferentes.

A equipe do Odin Teatret era formada na época por Roberta Carreri, Else Marie Laukvik, Iben Nagel Rasmussen, Tom Fjordefalk, Tage Larsen, Torgeir Wethal. Aos membros do grupo se juntaram dois jovens atores que haviam participado da Brigata Internazionale: Silvia Ricciardelli e Jan Torp. O grupo foi acompanhado igualmente por um jovem jornalista e crítico de teatro dinamarquês Stig Krabbe Barfoed, pelo fotógrafo Tony d'Urso e pelo historiador do teatro Ferdinando Taviani.

Outros participantes externos ao Odin foram convidados a se juntar à expedição. Entre os especialistas em ciências sociais, se encontrava Jacques Lizot, pesquisador francês do Laboratório de Antropologia Social do CNRS (Centre National de la Recherche Scientifique) ${ }^{4}$; Kenneth Gudeh, um antropólogo norte-americano, e Marie-Claude Muller, professora de linguística na UCV (Universidad Central de Venezuela). O Odin estava igualmente acompanhado, ao longo de toda a viagem, pelos membros da cooperativa cinematográfica Kurare. Os cineastas que faziam parte eram Santiago San Miguel, Liko Pérez, Eddy León, Iván Zambrano, Vytar Brenner, Fernando Campos e Manuel de Pedro. 


\section{Desenvolvimento do troc}

Finalmente, o Odin aceita a proposta e se lança na aventura. Nós tentamos aqui reconstituí-la, apoiando-nos em testemunhos dos atores e do diretor, sobre as matérias em jornais locais e sobre o filme rodado durante a experiência, Theatre meets ritual 5 .

Ao seguir os conselhos dos cineastas, o grupo se coloca em contato com Jacques Lizot, um antropólogo francês que vive dentro da comunidade indígena que eles pretendem encontrar. As necessidades a serem consideradas para a expedição não eram evidentes para eles. Primeiro, o grupo necessita de uma permissão especial para entrar em território Yanomami, que é protegido pelo Estado. Além do mais, o grupo deve prever muitos dias de viagem: de avião e em seguida de canoa para subir o Orénoque. A floresta é, além disso, um ambiente selvagem que exporia a equipe a perigos desconhecidos. Depois de alguns dias e numerosas negociações, o grupo obtém as permissões necessárias para viajar pela floresta. Eles conseguem aviões leves capazes de aterrissar em terrenos pequenos em plena Amazônia, para a surpresa extasiante e para o medo dos passageiros. Ao esperar que toda a equipe chegue e as condições meteorológicas melhorem, o grupo se hospeda uma noite numa casa de missionários. O primeiro contato com a comunidade indígena parece ter sido possível por intermédio do antropólogo Jacques Lizot e do diretor Eugenio Barba, segundo um artigo de um jornal local: "Eles convenceram o cacique que o grupo era uma tribo que vinha visitar os Yanomamis. Por fim, o xamã aceita e, no dia seguinte, os membros do Odin se aproximam da aldeia (shabono) Daya dos Yanomamis [...]" (Trujillo, 1976, p. n.i.).

$\mathrm{Na}$ realidade, como lembra Iben Nagel Rasmussen, o chefe da comunidade consente de se dobrar às solicitações dos estrangeiros com a condição de que eles levem um presente. Não apenas os presentes que os visitantes haviam previsto, mas alguns animais: filhotes de cachorro ${ }^{6}$ que, depois de muita discussão, se reduziram a apenas um.

A atriz descreve com ligeira ironia essa barganha que se desenrolou na conclusão da visita. 
O princípio de trocar dança por dança e canto por canto também é válido aqui, mas nós somos uma tribo desconhecida e espera-se de nós que demonstremos gentileza, de maneira extremamente concreta: potes, panelas, um filhote de cachorro vivo e bem nutrido [...] e, enfim, alguns metros de tecido vermelho, o único que os Yanomamis utilizam. Em troca, eles nos dão colares de dentes de anta, brincos de penas de tucano e um instrumento parecido com uma faca feita de osso de jaguar, para afiar flechas (Rasmussen, 2006, p. 95-97).

No dia seguinte, logo após uma reunião com todos os participantes, o grupo deixa a casa dos missionários e parte para a aldeia Yanomami. Os primeiros a chegar são Stig Krabbe $^{7}$ e a equipe cinematográfica. Todo o material necessário para filmar é preparado fora do olhar dos habitantes da aldeia. Em seguida, chegam os atores e Eugenio Barba. Depois de terem caminhado pela floresta, eles colocam seus figurinos e suas máscaras. Dois dos atores, Else Marie Laukvik e Tage Larsen, caminham em pernas de pau sobre o lodo. Eles tocam tambores e, lançando sinais de sua presença, se aproximam da aldeia. Eles chegam por um acesso baixo, o que os obriga a se dobrar, obrigando-os, também, a transportar horizontalmente seus companheiros que estão em pernas de pau. O grupo é recebido por sons e zumbidos, vindos dos índios que agitam seus corpos em movimentos ritmados. O Odin começa a desfilar em círculo, mostrando os personagens de sua parada de rua, deixando-se observar pelos habitantes da aldeia ${ }^{8}$. Segundo um jornalista,

No início, eles foram aceitos com certa surpresa e medo, mas rapidamente os índios responderam [...] com cantos e gritos. A integração aconteceu e os Yanomamis realizaram jogos de imitação (atuações) sobre suas lendas, mitos e ritos [...] (Trujillo, 1976, p. n.i.).

O troc se desenvolve no shabono, a grande casa, cujo telhado junta em um grande círculo todos os fogos domésticos da aldeia. Trata-se de um espaço localizado no centro da aldeia e partilhado por toda a comunidade. O diretor conta: "[...] eles nos conduziram ao fundo da Amazônia venezuelana, 
dentro de um shabono Yanomami, onde nós fomos recebidos de maneira ritual" (Barba, 1999, p. 217).

Depois da apresentação de alguns fragmentos do espetáculo de rua Le livre de danses, os Yanomamis responderam dançando. Os atores Else Marie Laukvik e Ian Torp apresentaram em seguida alguns números de extratos de seu espetáculo de clown Gøglere og Spaghetti ao qual se sucedeu Come! And the day will be ours apresentado pelo grupo inteiro. O xamã dos Yanomamis respondeu a este último, mimando e contando aos seus hóspedes o mito da tartaruga e do jaguar. Enfim, para concluir a visita, os membros das duas comunidades trocaram os presentes que citamos anteriormente. Esse tipo de troca é comum dentro de sociedades Yanomamis: "Os Yanomamis têm paixão pelo troc e pela barganha, não exatamente pela coisa em si que, afinal, tem apenas uma importância secundária, mas pelos elementos espirituais e sociais que a troca comporta de maneira global" (Alès, 2006, p. 172).

A equipe volta para a missão onde, em função da chuva, o avião não pode aterrissar. Ela é obrigada a ficar vários dias lá antes que o avião possa fazer o retorno para Caracas.

Durante esse troc, o Odin tem a oportunidade de analisar novamente seu modo de funcionamento, não apenas em nível das relações humanas no interior e no exterior do grupo, mas, sobretudo, no que concerne às modalidades de apresentação das suas obras. O lugar do espetáculo, sua apresentação, a disposição do público, assim como a quantidade de pessoas que devem assistir ao espetáculo não dependem mais somente de sua vontade e de sua disposição. Alguns dos critérios fundamentais, que haviam lhes guiado até então, deviam ser modificados nesse momento. O espaço de atuação é adaptado ao ambiente não convencional que lhes acolhe. A escolha habitual do grupo de se endereçar a uma pequena quantidade de espectadores não pode mais ser respeitada nesse novo contexto.

\section{Sensorialidade e Aprendizagem}

Em torno desse evento, numerosas são as relações sensoriais engendradas importantes para análise. Para esquematizar aqui alguns traços significativos, nós recorremos a matérias 
de jornal, ao testemunho do cineasta Manuel de Pedro, assim como a entrevistas com os atores do Odin.

Nos arquivos do CTLS (Centre for Theatre Laboratory Studies), em Holstebro, nós recolhemos extratos da imprensa local que nos ajudam a compreender essa aventura amazonense, mostrando toda sua complexidade.

Do ponto de vista sensorial, a linguagem empregada nos artigos que precederam e se seguiram ao intercâmbio tiveram um papel essencial na fabricação do imaginário desse evento. A maneira segundo a qual os jornalistas relatam, assim como os seus a priori sobre a comunidade indígena e sobre o Odin, veicularam uma certa imagem desse encontro: "[...] um dos grupos teatrais mais desenvolvidos da Europa e do planeta, se apresentou frente a um dos grupos mais primitivos, os índios Yanomamis [...]" (Trujillo, 1976, p. n.i.).

Numerosas foram igualmente as expectativas dos organizadores desse encontro. Primeiro, o fato de convidar a participar da expedição uma equipe multidisciplinar, tendo como objetivo o enquadramento desse evento do ponto de vista científico. Segundo, havia da parte dos jornalistas e cineastas uma tentativa de estabelecer uma relação direta entre os rituais Yanomamis e os espetáculos do Odin:

[...] segundo os antropólogos, o grupo de Yanomamis, apesar de ser (um dos povos) mais primitivo, é um coletivo essencialmente teatral. Eles vivem a realidade teatralmente: seus sortilégios, seus sacrifícios, seus ritos e seus mitos moldam uma realidade parateatral [...] (Trujillo, 1976, p. n.i.).

Esse raciocínio é revelador: ele procede de uma simplificação muito ingênua, tendendo a reduzir a cultura indígena a seus aspectos espetaculares e exageradamente interpretados. Esse raciocínio opera com o objetivo de deixar aparecer uma semelhança imaginada a priori entre as duas comunidades, que demonstraria a existência de uma suposta linguagem comum e confirmaria se as "[...] teorias do Odin se harmonizariam com a estrutura da linguagem indígena" (Trujillo, 1976, p. n.i.).

Manuel de Pedro, membro da cooperativa cinematrográfica Kurare, reivindica em numerosas ocasiões um olhar 
neutro sobre o acontecimento no que concerne às técnicas de filmagem empregadas, tanto quanto às escolhas estéticas. Ele reivindica um cinema documentário que utiliza a câmera como um olho exterior ao qual se recorre unicamente para observar e registrar os acontecimentos.

Eu não tenho uma proposta estética pessoal. O cinema
que eu faço, sendo de caráter documental, tenta sem-
pre não interferir com a realidade que eu registrei, que
eu filmei ou apresentei [...]. (Em relação a essa escolha)
meus filmes mais importantes são Iniciacion de uno
chaman ou El extranjero que danza no qual eu não fiz
nada além de observar a realidade [...] (De Pedro, 2010,
Comunicação Verbal) ${ }^{10}$.

Essa ideia de uma suposta neutralidade, hoje contestada, se apoiava igualmente sobre o discurso da imprensa. O jornalista Manuel Trujillo conta num artigo da imprensa sobre a decisão da equipe de cineastas de utilizar uma teleobjetiva para filmar em panorâmica, a fim de guardar uma distância dos participantes e de interferir o mínimo possível ao longo do troc. Essa escolha demonstra, então, segundo os jornalistas, sua vontade de efetivar uma filmagem real, objetiva: "Eles assinalam que não se trata de uma filmagem turística [...]" (Trujillo, 1976, p. n.i.).

O encontro com os Yanomamis foi provavelmente, em nível sensorial, uma das mais fortes experiências do grupo ao longo de toda sua carreira. Durante a minha segunda permanência em Holstebro, entre julho e agosto de 2010, eu tive a ocasião de entrevistar alguns dos atores do grupo em relação às suas experiências na América Latina. Dentre todas as narrativas e as lembranças que estão ligadas a esse continente, muitos deles escolheram focalizar suas entrevistas sobre as impressões vividas na Venezuela em 1976. Nessa época, a maior parte dos membros do Odin não falava espanhol, nem conhecia a América Latina e muito menos a floresta amazônica e as populações indígenas que lá viviam. É surpreendente ver a marca que o troc amazônico deixou neles, trinta e cinco anos mais tarde. Em suas narrativas fica explícito, evidentemente, o papel da dimensão sensorial no conjunto dessa experiência: as dificuldades que eles encontraram nas diferentes etapas da 
viagem; o choque experimentado face a um ambiente misterioso e desconhecido; o encontro com a comunidade Yanomami; a impossibilidade de se exprimir verbalmente e de se comunicar com os participantes locais e indígenas. Num segundo momento, a desorientação dos atores é dada principalmente em relação às reações dos Yanomamis como espectadores. De fato, quando o Odin apresenta seus materiais cênicos para a comunidade indígena, o grupo percebe reações inesperadas da parte do público indígena.

Segundo a descrição de Iben Nagel Rasmussen, os Yanomamis ficaram impassíveis enquanto assistiam a alguns números do espetáculo de clown:

\begin{abstract}
Eles olham com maravilhamento Else Marie (Laukvik) que come espagueti e que termina comendo o cadarço do seu sapato. Mas talvez os índios não saibam o que é espagueti, e nenhum deles utiliza sapatos. Aos seus olhos, as cenas deviam parecer completamente absurdas. Mas eles ficam alarmados cada vez que a equipe cinematográfica venezuelana cai na gargalhada de modo retumbante. Onde está o cômico? [...] (Rasmussen, 2006, p. 95-96).
\end{abstract}

Os números de clowns que tinham sido antes vistos e julgados pelo público europeu e de Caracas como divertidos e engraçados suscitaram nos índios um sentimento de desorientação, assim como uma incompreensão em relação ao riso dos cineastas. Ao contrário, durante a apresentação do espetáculo Come! And the day will be ours, os Yanomamis caíram na gargalhada. Esse espetáculo que supostamente fala da colonização e dos efeitos sobre as populações indígenas ameríndias, e que era normalmente percebido como trágico, provoca neles reações hilariantes. Esse comportamento é incompreensível aos olhos do Odin: "Eles encontram comicidade em Come! And the day will be ours. Pequenas risadas e zombaria acompanham as notas do violino, a luta dos pioneiros e os gritos desesperados do xamã [...]" (Rasmussen, 2006, p. 95-96).

Os atores ficam surpresos e desorientados pela atitude imprevisível dos Yanomamis: trata-se da primeira vez, por exemplo, na qual o grupo se encontra diante de um público que não está munido de códigos de interpretação necessários 
para a compreensão. O Odin se dá conta, então, de que a percepção de suas performances e sua decodificação não são em nada unívocas e que as reações do público não são universais. O grupo começa a se perguntar que papel a aprendizagem e a cultura jogam na percepção e na recepção do público. Em que medida a aprendizagem dos índios Yanomamis condicionou sua reação como público? Da onde vem os códigos expressivos utilizados pelos atores e porque eles não produzem os mesmos efeitos em diferentes públicos?

Durante o processo de criação de um espetáculo, é difícil prever as reações que o espetáculo irá provocar nos espectadores. Eugenio Barba define o espetáculo como uma esfinge, cujo mistério e o enigma podem acontecer somente por intermédio da interpretação dos espectadores:

\begin{abstract}
Quando o autor escreve o texto, ele constrói uma esfinge. Ele não conhece o enigma da esfinge. São o diretor e os atores que devem encontrar a solução. No momento em que eles a encontram, eles criam uma nova esfinge, cujo enigma não pode ser decifrado por eles: somente terceiros, os espectadores, serão capazes de fazê-lo" (Barba apud Taviani, 1981, p. 109).
\end{abstract}

Umberto Eco, linguista, filósofo e escritor italiano na sua obra intitulada L'œuvre Ouverte retoma o conceito expresso pelo diretor ítalo-dinamarquês: "Todas as obras [...] exigem de seu intérprete uma resposta pessoal e criativa: ele não pode compreendê-la sem reinventá-la em colaboração com o autor" (Eco, 1965, p. 16-17). Ele vai mais longe na sua proposta até comparar o espectador a um verdadeiro executante da obra: “A 'leitura', a 'contemplação', a 'apreciação' de uma obra de arte representa uma forma individual e implícita de 'execução' da obra" (Eco, 1965, p. 16-17). As teorias de Umberto Eco se juntam às ideias de Eugenio Barba no que concerne ao papel do espectador no teatro. Segundo Barba, o espectador participa fisicamente do trabalho dos atores em cena e interage com o diretor não apenas durante a interpretação da obra, mas ao longo de toda sua construção.

Para o filósofo Merleau-Ponty, a faculdade perceptiva consiste na capacidade de se apropriar de um objeto através 
de um processo interior e individual. A percepção não existe de maneira objetiva, mas ela é formada pela nossa experiência do mundo: "Um objeto não é efetivamente dado na nossa percepção, ele é retomado interiormente por nós, reconstituído e vivido por nós como algo ligado ao mundo, do qual nós partimos com nossas estruturas fundamentais e no qual ele é apenas uma das concretizações possíveis" (Merleau-Ponty, 1976, p. 383).

O corpo ocupa um lugar fundamental na percepção, pois trata-se de um instrumento por intermédio do qual o receptor percebe e lhe permite classificar, segundo suas referências pessoais, os estímulos que ele recebe: "Perceber, é se colocar presente frente a algum objeto com a ajuda do corpo, o objeto tem sempre seu lugar no horizonte do mundo, e a decodificação consiste em substituir cada detalhe no horizonte perceptível que lhe convém [...]" (Merleau-Ponty, 1996, p. 104).

Roland Barthes apoia essa tese, sublinhando o valor da biografia na recepção e na incorporação de uma obra:

Escrever significa desestabilizar o sentido do mundo, introduzir no mundo uma interrogação indireta, a qual o escritor, em um último suspense, se abstém em responder. A resposta será dada por cada um de nós, ao trazer sua história, sua linguagem, sua liberdade [...] (Barthes, 1963, Introdução).

No que concerne à função da aprendizagem e da cultura na decodificação de um espetáculo pelos espectadores, seria suficiente fazer referência a este axioma bem conhecido em psicologia experimental, assim como em psicobiologia e mesmo entre os economistas: não percebemos senão aquilo que aprendemos a perceber. Os economistas americanos Nancy J. Adler e Allison Gundersen no International dimensions of organizational behavior afirmam: "Padrões perceptivos são aprendidos. Nós não nascemos vendo o mundo de uma maneira particular, mas, sim, a experiência nos ensina a perceber o mundo de maneiras específicas" (Adler; Gundersen, 2008, p. 73).

As experiências pessoais do espectador e o contexto social, econômico e político no qual ele se situa, determinam a forma de ver, de perceber: 
A percepção é culturalmente determinada. Nós aprendemos a ver o mundo de uma maneira particular com base na nossa formação cultural. [...] Percebemos o que temos expectativa em perceber. Nós percebemos as coisas de acordo com o que aprendemos a ver, de acordo com o nosso mapa cultural [...] (Adler; Gundersen, 2008, p. 73).

O condicionamento de seu ambiente age de maneira tão forte que o espectador pode discernir e reconhecer no seu ato perceptivo o que ele aprendeu a perceber.

A experiência do Odin na Venezuela tem um lugar único no percurso do grupo. Se, de um lado, ela inaugura concreta e simbolicamente a constituição de uma rede entre o grupo e os países latino-americanos; de outro, ela marca profundamente e para sempre o trabalho cênico do grupo e as teorias que o sustentam.

O balanço final do troc da parte do diretor é muito positivo: "Ocorreu um encontro entre teatro e ritual. Ocorreu um troc muito tocante: os representantes de uma cultura que se crê no alto do progresso diante de uma comunidade em vias de desaparecer" (Barba, 1999, p. 219).

Quando do retorno do grupo em território venezuelano, vinte anos mais tarde, em 1996, ele afirma:

Para nós, voltar à Venezuela é muito significativo [...], foi o primeiro país que nós conhecemos na América Latina. Nossa visita em 1976 nos marcou profundamente, ela modificou algumas de nossas concepções. Esse acontecimento nos fez descobrir amigos de teatro que trabalham do outro lado do mar, e nos abriu as portas desse continente (Barba apud Torres Leon, 1996, s. p.).

E ainda: "Depois do Festival de Caracas, em 1976, a América Latina se tornou um ponto de referência essencial para fazer emergir as questões sobre o sentido de minha atividade teatral [...]" (Barba, 1999, p. 221).

Durante a análise desse troc, nós encontramos muitas dificuldades do ponto de vista metodológico. De início, é difícil reconstituir precisamente as diferentes etapas desse intercâmbio e avaliar seus efeitos para os Yanomamis. O filme Theatre 
meets ritual editado pelo Odin Teatret apresenta apenas uma versão breve e em grande parte descontextualizada do encontro. Segundo, os documentos existentes são principalmente os testemunhos dos atores do Odin, do cineasta Manuel de Pedro, assim como alguns artigos da imprensa local. O ponto de vista adotado na descrição toma, assim, muito mais a visão do Odin e dos organizadores da iniciativa. Nós não temos nenhum testemunho da visão da comunidade indígena. Por consequência, nós não temos nenhum traço no que concerne à recepção do acontecimento, tampouco suas repercussões no interior da comunidade indígena. 


\section{Notas}

${ }^{1}$ Essa palavra que designa notadamente uma "troca direta de bens sem intervenção de moeda" CNRS, Centre National de Ressources Textuelles et Lexicales (Disponível em: $<$ http://www. cnrtl.fr/definition/troc>; Acesso em: 2 abr. 2011), foi tomada pelo Odin Teatret na sua prática para indicar um intercâmbio de ações, de músicas, de danças ou de práticas artísticas entre duas comunidades determinadas.

${ }^{2}$ A ideia de Terceiro Teatro foi formulada durante o Primeiro Encontro de Teatro de Grupo organizado em Belgrado no outono de 1976 para definir o conjunto de grupos de teatro não reconhecidos pelo circuito convencional, tampouco pertencentes a arte de vanguarda.

${ }^{3}$ Nota de Tradução: nas citações de Trujillo, no texto original, não estão disponíveis as informações sobre a numeração das páginas consultadas. Para determinar esta situação, optamos por empregar p. n.i. (página não informada) ao lado das citações deste autor.

${ }^{4}$ Ele viveu vinte cinco anos de sua vida junto com a comunidade dos Yanomami de Karohi, e na época do troc ele vivia já há seis anos entre eles. Ele havia publicado recentemente o livro $L e$ Cercle des Feux. Faits et Dits des Indiens Yanomami, pela Éditions du Seuil em Paris em 1976.

${ }^{5} \mathrm{O}$ filme Theatre meets Ritual, Odin Teatret in Amazonia (1976) foi produzido pela cooperativa Kurare em 1976, em cores, duração de 25 min., sem narração.

${ }^{6}$ A atriz Else Marie Laukvik conta numa entrevista que os Yanomamis tinham pedido aos visitantes para lhes trazer de três a cinco filhotes de cachorro, mas ela conta que apenas um filhote foi levado pelo Odin ao cacique no momento da troca de presentes.

${ }^{7}$ Jornalista e crítico de teatro dinamarquês que colaborou durante anos com o Odin Teatret.

${ }^{8}$ Essas diferentes etapas são descritas pela atriz Iben Nagel Rasmussen (Rasmussen, 2006, p. 87).

${ }^{9}$ Tradução nossa.

${ }^{10}$ Entrevista a Manuel de Pedro Sobre su Filmografía más Destacada, entrevista realizada por Antonio Sutil e Laura Guevara. Disponível em: <http://vimeo.com/10943197>. Acesso em: 5 abr. 2011. 


\section{Referências}

ADLER, Nancy; GUNDERSEN, Allison. International Dimensions of Organizational Behavior. Independence: Thomson South-Western College Pub., 2008.

ALÈS, Catherine. Yanomami, l'ire et le Désir. Paris: Karthala Éditions, 2006.

BARBA, Eugenio. Théâtre, Solitude, Métier, Révolte. Montpellier: Collection Les Voies de l'Acteur, l'Entretemps Éditions, 1999.

BARTHES, Roland. Sur Racine. Paris: Seuil, 1963.

CHRISTOFFERSEN, Erik Exe. The Actor's Way. London: Routledge, 1993.

DE PEDRO, Manuel. Entrevista a Manuel de Pedro Sobre su Filmografía más Destacada. Entrevista realizada por Antonio Sutil e Laura Guevara. Disponível em: <http://vimeo. com/10943197>. Acesso em: 5 abr. 2011.

D’URSO, Tony; TAVIANI, Ferdinando. L'Étranger qui Danse: album de l'Odin Teatret 19721977. Rennes: Maison de la Culture de Rennes, 1977.

ECO, Umberto. La Poétique de l'CEuvre Ouverte. In: ECO, Umberto. L'Guvre Ouverte. Paris: Editions du Seuil, 1965. P. 15-40.

LIZOT, Jacques. Le Cercle des Feux: faits et dits des Indiens Yanomami. Paris: Editions du Seuil, 1976.

MERLEAU-PONTY, Maurice. Phénomènologie de la Perception. Paris: Editions Gallimard, 1976.

Merleau-POnTy, Maurice. Le Primat de la Perception et ses Conséquences Philosophiques. Lagrasse: Editions Verdier, 1996.

RASMUSSEN, Iben Nagel. Il Cavallo Cieco: dialoghi con Eugenio Barba e altri scritti. Roma: Memorie di Teatro Bulzoni editore, 2006.

TAVIANI, Ferdinando (Org.). Il Libro dell'Odin. Milano: Feltrinelli, 1981.

TORRES LEON, Vicglamar. Segun Eugenio Barba el Odin Teatret Vino tras Leones Feroces. EI Universal, Caracas, n. 31128, 7 mar. 1996.

TRUJILlO, Manuel. Experiencia Unica en el Mundo: uno de los grupos teatrales mas avanzados intercambia actuacion con otro de los mas primitivos, 1976. Documento do Arquivo do Centre for Theatre Laboratory Studies (CTLS) localizado no Odin Teatret em Holstebro, Dinamarca. 
Arianna Berenice De Sanctis é doutoranda em Estudos Teatrais, no Laboratório de Etnocenologia, na Université Paris 8 Vincennes Saint-Denis sob orientação de Jean-Marie Pradier em cotutela com a Universitat de Barcelona com a orientação de Lluis Masgrau. Sua pesquisa versa sobre o trabalho do Odin Teatret na América Latina. Ela é mestre em teatro pela Università di Roma 3 com orientação de Nicola Savarese. Ela é atriz, diretora e professora no grupo ítalo-argentino La Teatreria.

E-mail: ariappappa@yahoo.it

Traduzido do original em francês por Gilberto Icle e revisado por Márcio Müller.

Recebido em novembro de 2011 Aprovado em março de 2012 